\title{
A!
}

This is an electronic reprint of the original article.

This reprint may differ from the original in pagination and typographic detail.

Ahvenniemi, E.; Karppinen, M.

\section{ALD/MLD processes for Mn and Co based hybrid thin films}

Published in:

Dalton Transactions

DOI:

$10.1039 / \mathrm{c} 6 \mathrm{dt00851h}$

Published: 01/01/2016

Document Version

Peer reviewed version

Please cite the original version:

Ahvenniemi, E., \& Karppinen, M. (2016). ALD/MLD processes for Mn and Co based hybrid thin films. Dalton Transactions, 45(26), 10730-10735. https://doi.org/10.1039/c6dt00851h

This material is protected by copyright and other intellectual property rights, and duplication or sale of all or part of any of the repository collections is not permitted, except that material may be duplicated by you for your research use or educational purposes in electronic or print form. You must obtain permission for any other use. Electronic or print copies may not be offered, whether for sale or otherwise to anyone who is not an authorised user. 


\section{Dalton Transactions}

\section{ARTICLE}

\section{ALD/MLD processes for Mn and Co based hybrid thin films}

Received 00th January 20xx Accepted 00th January $20 x x$

DOI: $10.1039 / \times 0 \times x 00000 x$

www.rsc.org/

\section{E. Ahvenniemi and M. Karppinen†}

Here we report the growth of novel hybrid transition metal-organic thin-film materials consisting of manganese or cobalt as the metal component and terephthalate as the rigid organic backbone. The hybrid thin films are deposited by the currently strongly emerging atomic/molecular layer deposition (ALD/MLD) technique using the combination of metal $\beta$-diketonate, i.e. $\mathrm{Mn}$ (thd) $)_{3}, \mathrm{Co}(\mathrm{acac})_{3}$ or $\mathrm{Co}(\mathrm{thd})_{2}$, and terephthalic acid (1,4-benzenedicarboxylic acid) as precursors. All the processes yield homogeneous and notably smooth amorphous metal-terephthalate hybrid thin films with growth rates of 1-2 $\AA$ /cycle. The films are stable towards humidity and withstand high temperatures up to 300 or $400{ }^{\circ} \mathrm{C}$ under oxidative or reductive atmosphere, respectively. The films are characterized with XRR, AFM, GIXRD, XPS and FTIR techniques.

\section{Introduction}

Our future high-tech applications are increasingly based on (ultra)thin films with atomic-level control of the film thickness and composition over different structurally challenging and/or large-area surfaces. So far the only deposition technique meeting the criteria of industrial feasibility for such state-ofthe-art thin films is the atomic layer deposition (ALD) method; ${ }^{1}$ it is based on self-limiting gas-to-surface reactions of mutually separated gas pulses of two (or more) different precursors and enables the fabrication of high-quality conformal coatings of various simple inorganic compounds for e.g. advanced semiconductor, catalyst, sensor and barrier-layer applications.

Currently there is a strong strive to extend the ALD technique to increasingly complex compounds and material compositions to better answer to the future demands. This includes not only various ternary and quaternary inorganic compounds, 2,3 but also inorganic-organic hybrids realized through the combined ALD/MLD technique; ${ }^{4}$ here the MLD (molecular layer deposition) method first developed for purely organic materials is based on organic precursors only and yields through sequential gas-surface reactions organic polymeric thin films in a molecular layer-by-layer manner like the original ALD method for the inorganics. ${ }^{5,6}$ While there are not much more than a handful of publications on purely organic M LD films, the interest towards developing new ALD/MLD processes for the inorganic-organic hybrid materials is rapidly growing. ${ }^{4} \mathrm{M}$ ost of the early ALD/M LD works concern very few metal constituents (mainly Al, Zn, Ti and $\mathrm{Zr})^{1,4,7-13}$ but in the most recent works the technique has been successfully extended to some $3 d$, $4 f$ and alkali metal based hybrid thin films with interesting

\footnotetext{
t Laboratory of Inorganic Chemistry, Department of Chemistry, Aalto University, P.0. Box 16100, Fl-00076 Aalto, Espoo, Finland.

E-mail: maarit.karppinen@aalto.fi; Fax: +358 9462 373; Tel: +358 503841726
}

luminescence and electrochemical properties. ${ }^{14-17}$ Hybrid thinfilm materials based on $3 d$ transition elements with partiallyfilled $d$ orbitals would be attractive due to their potential to show e.g. exciting electrical, magnetic and catalytic properties; in particular, based on the experiences from conventional inorganic compounds, manganese and cobalt would be among the most interesting $3 \mathrm{~d}$ metal constituents.

In conventional ALD for the inorganics, $\beta$-diketonate complexes based on the 2,2,6,6-tetramethyl-3,5-heptanedione (thd) and acetylacetonate (acac) ligands are commonly employed as precursors for e.g. manganese and cobalt, ${ }^{18,19}$ and have already been successfully utilized even in some ternary and quaternary oxide processes. ${ }^{18-22}$ Even though the $\beta$ diketonate precursors work very well in ordinary ALD processes, they have been little utilized in the hybrid ALD/MLD processes since they do not react with the typical alcohol-based MLD precursors. Only very recently when carboxylic acids ${ }^{10,23}$ were employed as organic precursors the first $\beta$-diketonate based ALD/MLD processes were developed for $\mathrm{Cu}(\text { thd })_{2},{ }^{14} \mathrm{Li}($ thd $),{ }_{17}$ $\mathrm{Zn}\left(\mathrm{CH}_{3} \mathrm{CO}_{2}\right)_{2}{ }_{2,25}$ and Eu(thd $)_{3}{ }^{15}$ In these depositions the organic precursor was aromatic with a rigid benzene ring structure which is beneficial for the film growth; ${ }^{4}$ the aromaticity is also believed to help to preserve the electrical properties of the inorganic constituent, ${ }^{11,12}$ giving the resilient hybrid materials exciting features in electronics. In literary, linear carboxylic acids have been employed as well to fabricate e.g. iron and aluminium based hybrid materials. ${ }^{26-28}$

In this paper, we introduce novel ALD/MLD processes for manganese and cobalt based hybrid thin films using $\mathrm{Mn}(\text { thd })_{3}$, $\mathrm{Co}(\mathrm{acac})_{3}$ and $\mathrm{Co}(\text { thd })_{2}$ as the metal precursors and benzene1,4-dicarboxylic acid (1,4-BDC) or so-called terephthalic acid (TPA) as the organic precursor, see Fig. 1. We will moreover show that the film growth rate is essentially higher for the process in which the cation in the metal precursor is divalent, i.e. with $\mathrm{Co}(\text { thd })_{2}$, presumably due to the less severe steric hindrance. 
$\mathrm{Mn}(\mathrm{thd})_{3}$

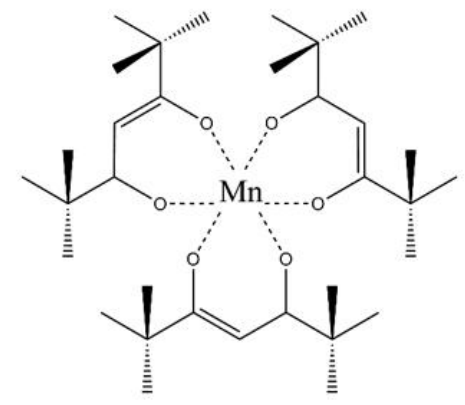

$\mathrm{Co}(\mathrm{acac})_{3}$<smiles>CC1=CC(C)O[C@]2(O1)OC(C)C=C(C)O[C@@]21OC(C)=CC(C)O1</smiles>

Co(thd) $)_{2}$

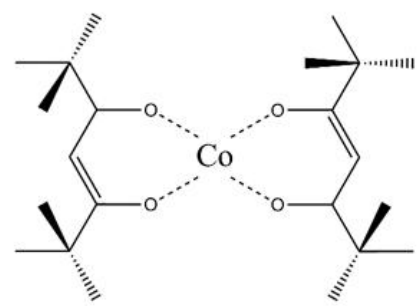

$1,4-B D C(T P A)$

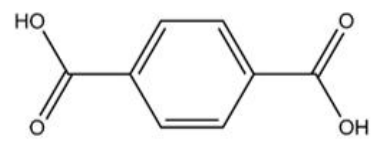

Fig. 1 Precursors employed in the present ALD/M LD processes.

\section{Results and discussion}

We first investigated the saturation behaviour of the surface reactions for our $\mathrm{Mn}$ (thd $)_{3}-\mathrm{TPA}, \mathrm{Co}(\mathrm{acac})_{3}-\mathrm{TPA}$ and $\mathrm{Co}(\text { thd })_{2}-$ TPA processes by changing the precursor pulse lengths one at the time in each process and monitoring the resultant film growth-per-cycle (GPC) value based on XRR data after 400 deposition cycles, see Fig. 2. In these experiments the deposition temperature was set to $200^{\circ} \mathrm{C}$ for all the three processes, and the precursor pulse length was fixed at $2 \mathrm{~s}$ for the metal precursor when the TPA pulse length was varied, and at $10 \mathrm{~s}$ for the TPA pulse when the metal precursor pulse length was varied. From Fig. 2, the surface reactions indeed saturate for relatively short pulse lengths, even though the precursor sublimation temperatures applied here are relatively low, i.e. $105^{\circ} \mathrm{C}$ (c.f. $133^{\circ} \mathrm{C}^{18}$ ) for $\mathrm{Mn}(\text { thd) })_{3}, 128^{\circ} \mathrm{C}$ (c.f. $180^{\circ} \mathrm{C}^{29}$ ) for $\mathrm{Co}(\mathrm{acac})_{3}, 100^{\circ} \mathrm{C}$ (c.f. $110^{\circ} \mathrm{C} 30$ ) for $\mathrm{Co}(\text { thd })_{2}$ and $180^{\circ} \mathrm{C}$ (c.f. $220^{\circ} \mathrm{C}^{24}$ ) for TPA. We like to emphasize that the use of the lower
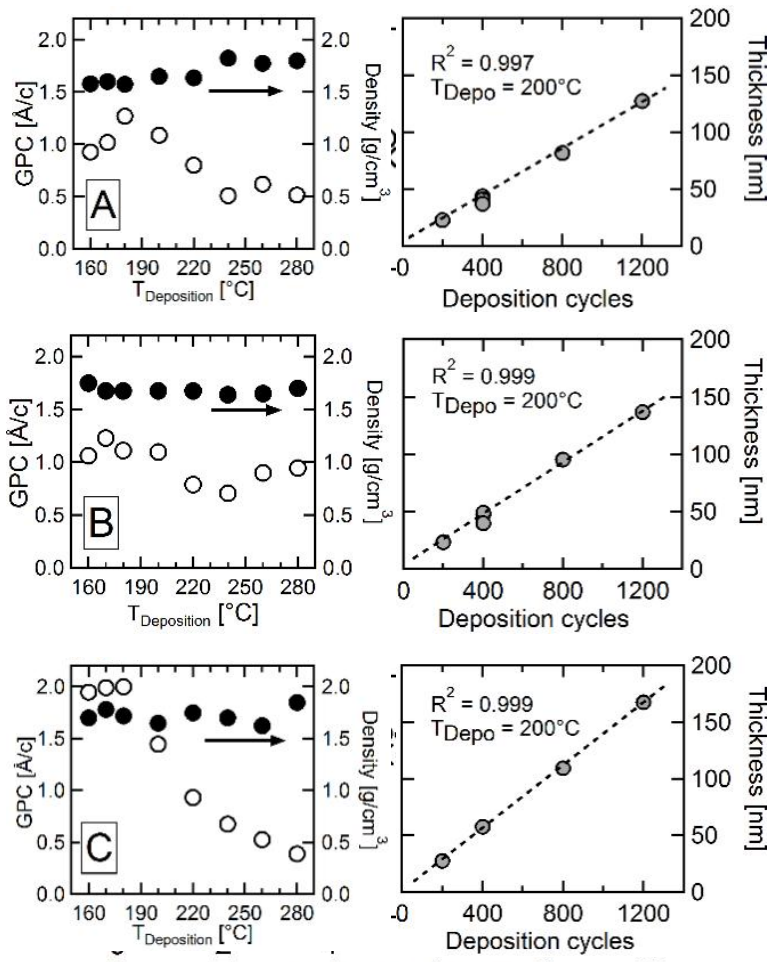

Pulse length [s]

Fig. 2 Growth-per-cycle (GPC) as a function of the metal precursor (0) and TPA (x) pulse lengths for the three ALD/MLD processes, $M n(\text { thd })_{3}$-TPA (A), Co(acac) $)_{3}$ TPA (B) and Co(thd $)_{2}$-TPA (C). The deposition temperature was set to $200{ }^{\circ} \mathrm{C}$ and the pulse/purge lengths of the other precursor were fixed to $2 \mathrm{~s} / 5 \mathrm{~s}$ for each metal precursors and to 10 $\mathrm{s} / 20 \mathrm{~s}$ for TPA. The estimated uncertainties in the GPC, density and thickness values are within the sizes of the marks.

sublimation temperatures is advantageous as it allows us to also use lower deposition temperatures and thereby employ the processes for e.g. temperature-sensitive substrates. For the rest of the experiments the pulse and purge lengths were fixed as follows: 5 s metal precursor $+2 \mathrm{~s} \mathrm{~N}_{2}$ purge $+10 \mathrm{~s}$ TPA $+20 \mathrm{~s} \mathrm{~N}_{2}$ purge.

Then the temperature window for the "ideal ALD/MLDtype" growth was searched for within $160-280^{\circ} \mathrm{C}$ by monitoring the values for GPC, film density and film roughness (all determined from XRR data) as a function of the deposition temperature, see Fig. 3 left panel. Note that the relevant deposition temperature range was limited by the TPA sublimation temperature in the low temperature side $\left(180^{\circ} \mathrm{C}\right)$ and the emergence of CVD-type growth accompanied with desorption of organic material in the high temperature side $\left(280^{\circ} \mathrm{C}\right)$. Temperatures lower than the sublimation temperature of TPA were however tested as well with the anticipation that the lower deposition temperature might promote the formation of crystalline phases as was recently seen in the case of our $\mathrm{Cu}(\text { thd })_{2}$-TPA process. ${ }^{14}$ By monitoring solely the growth rate, it is not straightforward to claim any optimal deposition temperature window for any of the three processes investigated. However, as the density and roughness values remain essentially constant in the temperature range of 200 $220{ }^{\circ} \mathrm{C}, 170-260{ }^{\circ} \mathrm{C}$ and $180-260{ }^{\circ} \mathrm{C}$ for the $\mathrm{Mn}$ (thd) $)_{3}$-TPA, $\mathrm{Co}(\mathrm{acac})_{3}$-TPA and $\mathrm{Co}(\text { thd })_{2}$-TPA processes, respectively, and 

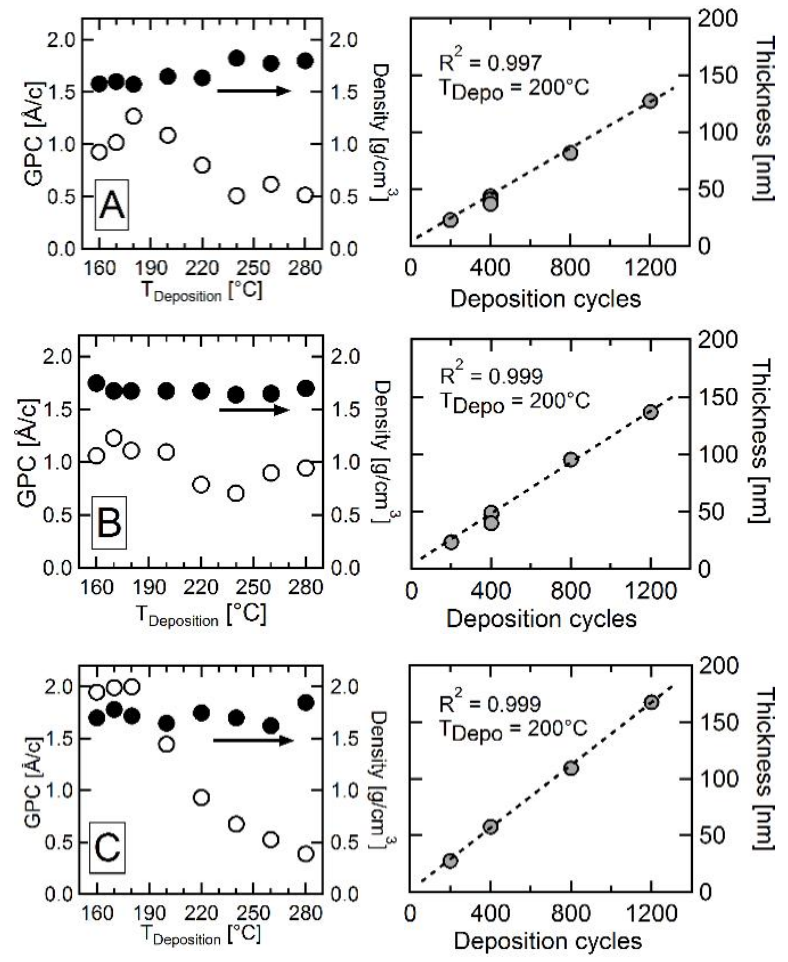

Fig. 3 Left column: Growth-per-cycle (GPC) and film density for the three ALD/MLD processes, Mn(thd) $)_{3}$-TPA (A), Co(acac) $)_{3}$-TPA (B) and Co(thd) $)_{2}$-TPA (C). Right column: The growth linearity of films deposited at $200^{\circ} \mathrm{C}$, using the optimized pulsing parameters. The estimated uncertainties in the GPC, density and thickness values are within the sizes of the marks.

the films' surfaces remain appreciably smooth (with a roughness value as low as $0.2 \mathrm{~nm}$ for ca. $30 \mathrm{~nm}$ thick films), we decided to fix the deposition temperature at $200^{\circ} \mathrm{C}$ for the rest of the experiments. At this deposition temperature the essentially ideal ALD/MLD behaviour, i.e. linear dependency of the film thickness on the number of ALD/M LD cycles, is seen for all the three processes as demonstrated in Fig. 3, right panel.

In Fig. 4 we display the XRR patterns for a series of films with different thicknesses (for all the three processes) where the thickest films are on the top and the thinnest on the bottom of the figure; the patterns correspond to the thickness data shown in the right panel of Fig. 3. The slow overall decay rates of intensity and oscillations indicate that the films are appreciably homogeneous and smooth on their surface;31,32 it should be noted that care was taken to keep the substrates always of the same size as the size somewhat affects the initial decay rate. Then the distance between two amplitudes in the XRR pattern corresponds to the film thickness. As seen for the thickest film from the $\mathrm{Co}(\mathrm{acac})_{3}$-TPA process, secondary oscillations arise, indicating a non-perfect deposition process of thicker films with a formation of a thin secondary layer. Apparently the film quality is better for the two thd-based processes than for the Co(acac) $)_{3}$-TPA-process.

Fig. 4 XRR patterns for films with different thicknesses deposited with the three ALD/M LD processes, Mn(thd) ${ }_{3}$-TPA (A), Co(acac) $)_{3}$ TPA (B) and Co(thd) $)_{2}$-TPA (C): the order is in each case from the thinnest (bottom) to the thickest (top).

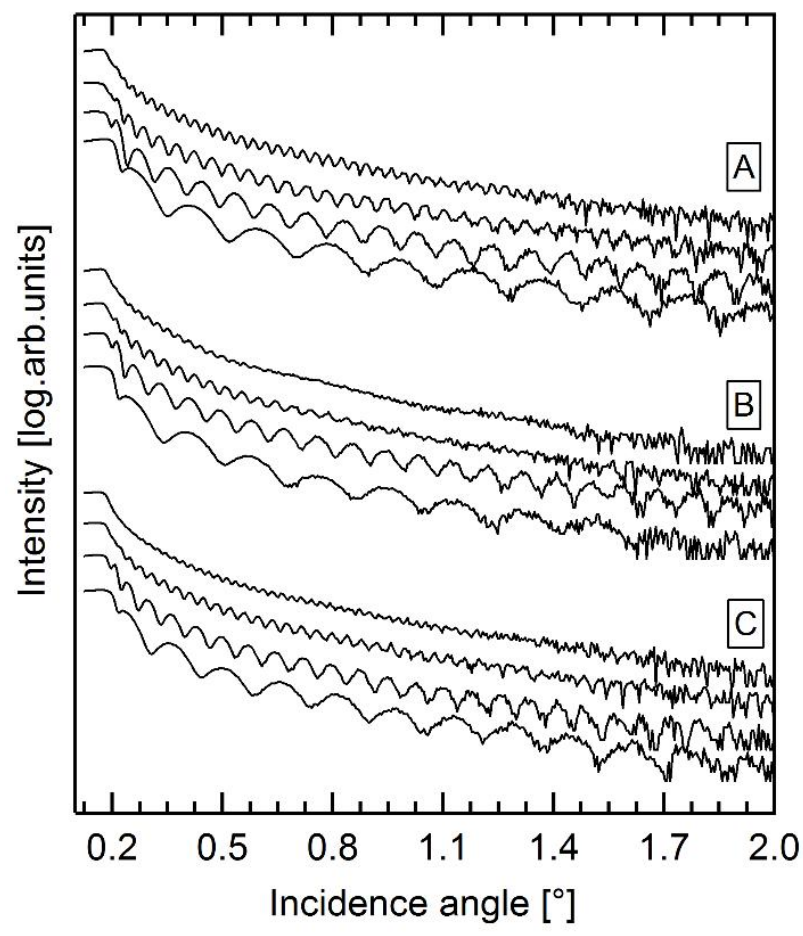

This is in line with the fact that typically the thd-precursors have been favoured over the acac-precursors in the conventional ALD technology despite their higher prices, which is probably due to the better overall reactivity and ligand detachment properties.

Since we recently found a narrow deposition temperature range for our $\mathrm{Cu}(\text { thd })_{2}$-TPA process ${ }^{14}$ where the process yielded crystalline metal-organic framework (MOF) films, we systematically checked the possible crystallinity of the present samples as well by GIXRD measurements; however, all the present thin films were found to be amorphous, even though a slight density drop was seen for the Mn-TP films deposited at lower temperatures, similarly to the case with the Cu-TP films.

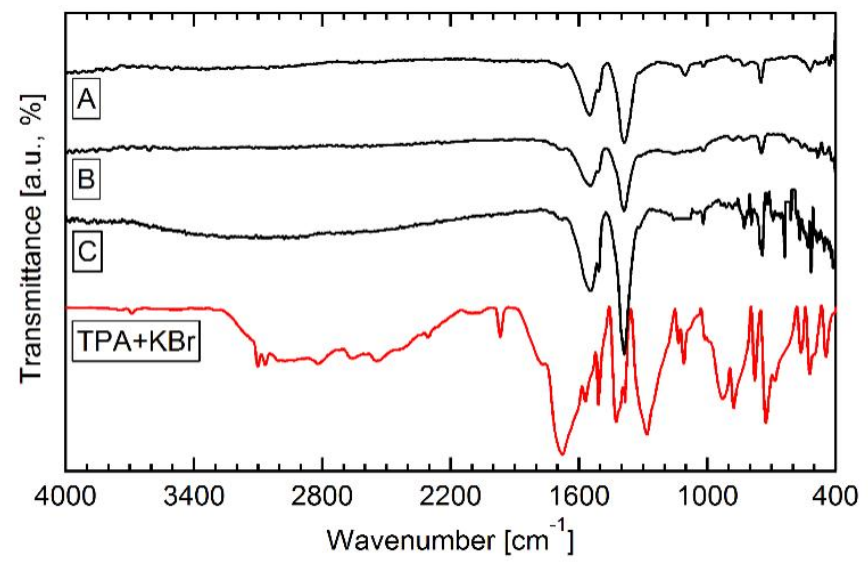

Fig. 5 FTIR spectra for films deposited with the three $A L D / M L D$ processes, $M n(\text { thd })_{3}-T P A$ (A), Co(acac) $)_{3}$ TPA (B), Co(thd) ${ }_{2}-$ TPA (C) and a spectrum for the TPA precursor ( $+\mathrm{KBr}$ ) for reference. 


\section{Dalton Transactions}

\section{ARTICLE}
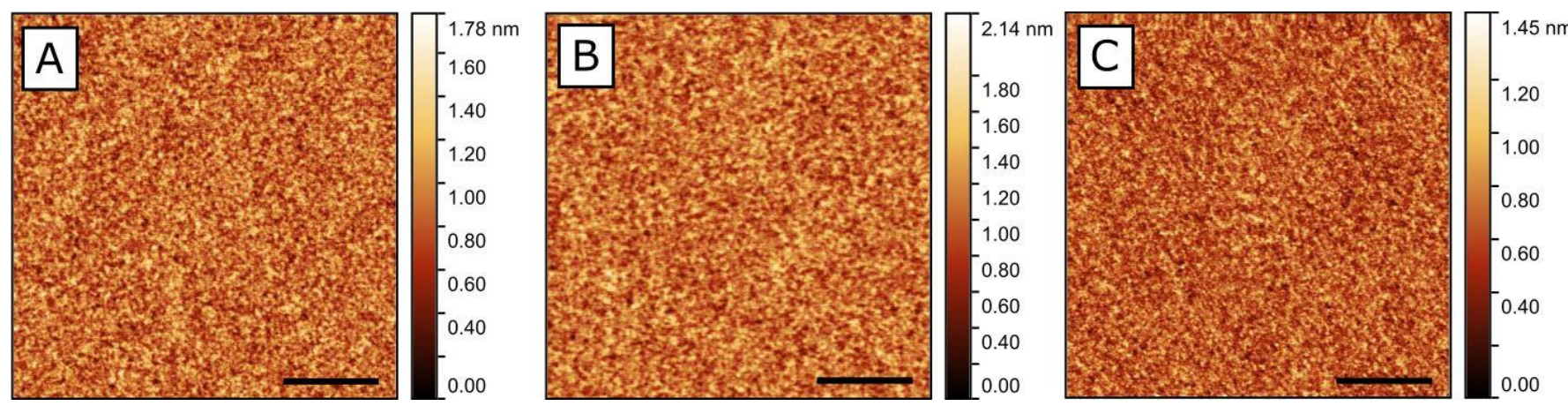

Fig. 6 AFM images for films deposited with the three ALD/M LD processes, $\mathrm{Mn}(\text { thd })_{3}$-TPA (A), Co(acac) $)_{3}$ TPA (B) and Co(thd) $)_{2}$-TPA (C), revealing smooth films despite the exposure to moisture. The roughness and thickness values for the films are $0.4 \mathrm{~nm} / 32.6 \mathrm{~nm}, 0.2 \mathrm{~nm} / 42.1 \mathrm{~nm}$ and $0.2 \mathrm{~nm} / 37.4 \mathrm{~nm}$, respectively. The black indicator bar represents $500 \mathrm{~nm}$ distance on AFM figures.

For bulk samples, crystalline terephthalate structures have been reported for divalent Co(II), but not for trivalent cations. 33

Fourier-transform infrared spectroscopy was employed to verify the organic constituent in the films and its coordination to the metal; representative spectra are shown in Fig. 5. As described by e.g. Klepper et al., ${ }^{34}$ the type of the carboxylate coordination can be evaluated from the symmetric $\left(v_{s}\right)$ and asymmetric $\left(v_{\text {as }}\right)$ stretches of the COO-group. The peaks found for all the precursor combinations in the signature wave number area are at ca. $1615 \mathrm{~cm}^{-1}$ (shoulder), $1575 \mathrm{~cm}^{-1}$ (shoulder), $1555 \mathrm{~cm}^{-1}(\mathrm{~s}), 1515 \mathrm{~cm}^{-1}(\mathrm{~m}), 1425 \mathrm{~cm}^{-1}$ (shoulder), $1405 \mathrm{~cm}^{-1}$ (shoulder) and $1390 \mathrm{~cm}^{-1}(\mathrm{~s})$. The peaks at $1390 \mathrm{~cm}^{-1}$ and $1575-1550 \mathrm{~cm}^{-1}$ correspond to $\Delta\left(v_{\mathrm{s}}-\mathrm{v}_{\mathrm{as}}\right)$ of ca. $160-185 \mathrm{~cm}$ 1 , thus the bonding scheme is dominantly of the bridging type. ${ }^{34}$ The wide peaks indicate most likely the amorphous nature of the films with slightly varying surroundings for the $\mathrm{COO}$ - group. The FTIR spectra do not show any peaks in the $2000-3200 \mathrm{~cm}^{-1}$ area, which would correspond to adsorbed $\mathrm{H}_{2} \mathrm{O}$, unreacted carboxylic acid groups or carbohydrate-based impurities.

Presented in Fig. 6, the quality of the amorphous films was further evaluated using atomic force microscopy (AFM). The root-mean-square roughness values were $0.2 \mathrm{~nm}$ (total thickness $32.6 \mathrm{~nm}), 0.2 \mathrm{~nm}(42.1 \mathrm{~nm})$ and $0.2 \mathrm{~nm}(37.4 \mathrm{~nm})$ for the $\mathrm{M} \mathrm{n}(\text { thd })_{3}-$ TPA, Co (acac) $)_{3}$-TPA and Co(thd $)_{2}$-TPA processes, respectively, well agreeing with the roughness values derived from the XRR data $( \pm 0.1 \mathrm{~nm}$ ). Also remarkably, the lack of any high features for any of the films indicates that the surfaces are essentially free from surface contamination by adsorbed particles. The samples were stored under 30\% RH atmosphere for 60 days prior to the AFM measurements.

To further investigate the stability of our new $\mathrm{M} \mathrm{n}$ - and Cobased hybrid thin films we exposed the films for up to 40 days to precisely controlled atmosphere of ca. $30 \%$ relative humidity. There were no notable visual changes, and the thickness changes of the films were within $1 \mathrm{~nm}$, which is a typical error margin for XRR thickness measurements. The inertness of the films against humidity arise most likely from the completely coordinated amorphous structure, and due to the reduction of gas absorption through the sealed well-stacked film. Then the thermal stability of the films was studied by heating them in an RTA oven for 15 minutes under different atmospheres. The films remained intact up to ca. $300^{\circ} \mathrm{C}$ in $\mathrm{O}_{2}$ and up to ca. $400^{\circ} \mathrm{C}$ in $\mathrm{Ar}$.

Finally we discuss the film growth rates for the three processes, $\mathrm{Mn}$ (thd) $)_{3}$-TPA, Co(acac) $)_{3}$ TPA and Co(thd) $)_{2}-$ TPA; in the first two processes the transition metal ( $\mathrm{Mn}$ or $\mathrm{Co}$ ) in the inorganic precursor is trivalent, while being divalent in the last process. The GPC values for the processes where the metal precursor is trivalent were ca. 1.0-1.2 $\AA$ /cycle, while being clearly higher. i.e. $1.5 \AA$ /cycle, for the Co(thd) $)_{2}$-TPA process where cobalt is divalent. The growth rate seems to correlate with the area taken by the precursor ligands which remains after the precursor has attached to the surface group. Similar observations/conclusions have been reported by e.g. Ylilammi et al. ${ }^{35}$ and Lie et al., ${ }^{21}$ and also in some other previous studies. ${ }^{36}$ Assuming the precursors detach one of their ligands when reacting with the surface, the $\mathrm{Mn}$ (thd $)_{2}$ - group (corresponding to the lowest GPC value) is by six methyl groups larger than the Co(acac) $)_{2}$ group, and as they both take notably more space compared to the Co(thd)- group corresponding to the highest GPC value, we may indeed conclude that for the present $A L D / M L D$ processes the growth rate inversely depends on the surface area required by the precursor ligands. Very similar correspondence was seen for example for the quaternary oxide process among the $\mathrm{La}(\text { thd })_{3}, \mathrm{Sr}(\text { thd })_{2}$ and $\mathrm{Co}(\mathrm{acac})_{3}$ precursors. ${ }^{22}$ The situation is illustrated as a two-dimensional model for simplicity in Fig. 7 where in the left panel, the ligands from a divalent cation precursor have clearly more space to promote further growth of the film (the space occupied by an individual precursor illustrated with a green box) compared to the right panel case where the ligands from a trivalent cation precursor 
block some of the surface sites and thus the film growth is essentially less than a monolayer per cycle.
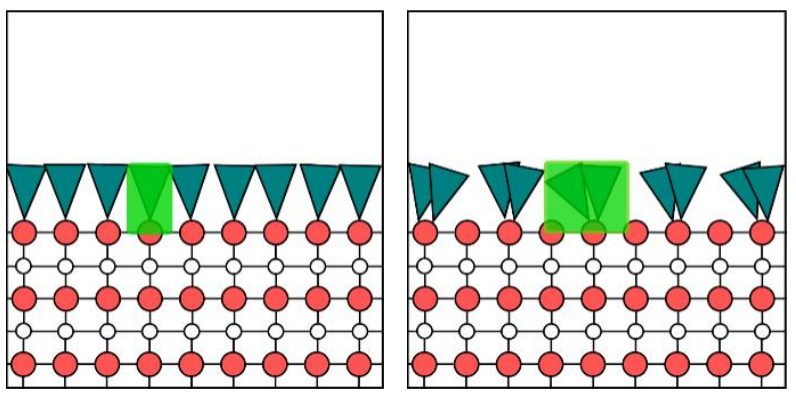

Fig. 7 Schematic illustration (in two-dimension) of the space occupied by bulky coneshaped ligands in precursors of divalent (left) and trivalent (right) metal cations.

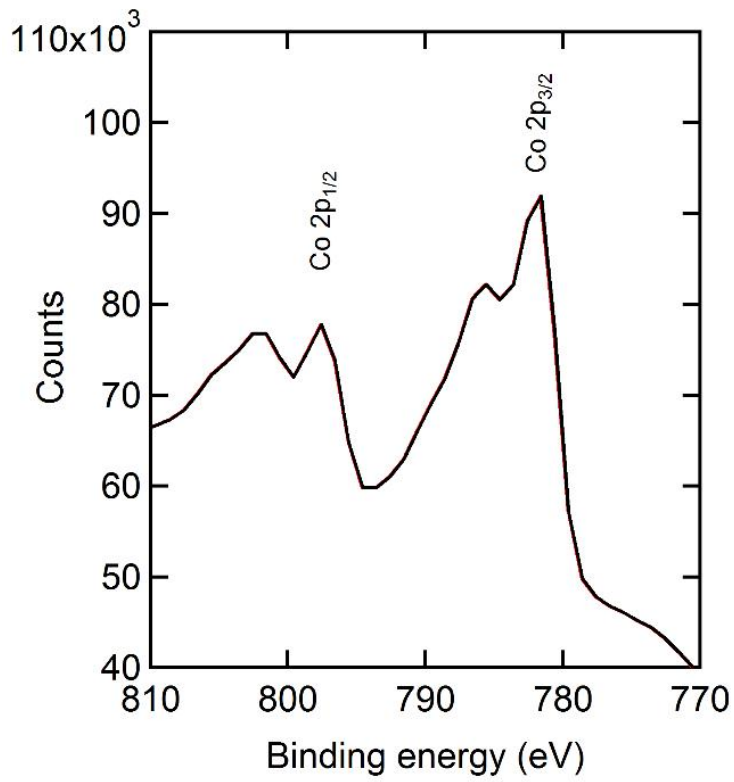

Fig 8. Co $2 p$ XPS spectrum for a Co-TP hybrid thin film deposited from Co(thd $)_{2}$ and TPA precursors.

Another interesting question related to the different oxidation states of the metal species in our precursors concerns weather the divalent state of cobalt in the $\mathrm{Co}(\text { thd })_{2}$ precursor is maintained upon the ALD/MLD process; we carried out XPS measurements to clarify this. The XPS spectrum shown in Fig. 8 for a resultant film from the Co(thd) ${ }_{2}$-TPA process reveals the Co $2 p_{3 / 2}$ and $2 p_{1 / 2}$ peaks at ca. 785.5 and $802.2 \mathrm{eV}$, respectively, followed by prominent satellite peaks on the higher-energy sides of the main peaks. The presence of intense satellite peaks is an indication of the divalent state of cobalt, ${ }^{37}$ and hence we can conclude that the divalent state of cobalt in the $\mathrm{Co}(\text { thd })_{2}$ precursor is at least partly maintained upon the ALD/MLD process. Additionally, our XPS measurements confirmed (the wider-energy-range spectrum not shown here) that our hybrid films are free from any significant impurities, the only impurity seen being $0.4 \%$ nitrogen, probably adsorbed from the air.

\section{Experimental}

Thin films of $\mathrm{Mn}$-TP and Co-TP were successfully grown in a commercial ALD reactor (F-120, ASM M icrochemistry Ltd.) using $\mathrm{Mn}$ (thd) ${ }_{3} \quad$ (thd: 2,2,6,6-tetramethyl-3,5-heptanedione), $\mathrm{Co}(\mathrm{acac})_{3}$ (acac: acetylacetonate) and $\mathrm{Co}(\text { thd })_{2}$ as metal precursors, and benzene-1,4-dicarboxylic acid (1,4-BDC or TPA) as the organic precursor. The $\mathrm{Co}(\text { thd })_{2}$ and $\mathrm{Mn}$ (thd) ${ }_{3}$ precursors were prepared in-house by synthesis method described elsewhere, ${ }^{38}$ while commercial sources were used for $\mathrm{Co}(\mathrm{acac})_{3}$ (Sigma, CAS: 21679-46-9, 99.99\%) and terephthalic acid (Tokyo Chemical Industry CO., Ltd, CAS: 100-21-0). The sublimation temperatures of the solid precursors were fixed at 105, 128, 100 and $180{ }^{\circ} \mathrm{C}$ for $\mathrm{Mn}$ (thd) $)_{3}, \mathrm{Co}(\mathrm{acac})_{3}, \mathrm{Co}(\text { thd })_{2}$ and TPA, respectively, based on our preliminary data from thermogravimetric analysis (TG; Perkin-Elmer TGA 7) and sublimation rates in the F-120 reactor. Nitrogen (99.999\%, 300 sccm, Schmidlin UHPN $3000 \mathrm{~N}$ generator) was used as the carrier and purge gas in the depositions with the background pressure of ca. 2-3 mbar (1.5-2 Torr). All the depositions were performed on silicon (p-type, Si(100), Okmetic Ltd.) substrates.

Grazing incidence X-ray diffraction (GIXRD; PANalytical model X'Pert PRO diffractometer, $\mathrm{Cu}$ Ka radiation) was used to investigate the possible crystallinity of the films measured at grazing incidence angle of $0.5^{\circ}$ from $2 \theta=5-70^{\circ}$, and X-ray reflectivity (XRR) measurements using the same equipment to determine the film thickness, density and roughness. The film thickness values given are averages of the values calculated using the direct calculation and the Fourier methods. The film roughnesses were further analysed with atomic force microscopy (AFM; Veeco Dimension 5000) with 1.0 - $1.5 \mathrm{~Hz}$ scan speed in tapping mode. The organic component was verified and the coordination type investigated using Fourier transform infrared spectroscopy (FTIR; Nicolet Magna-IR Spectrometer 750 ), where the average of 32 scans with $4 \mathrm{~cm}^{-1}$ resolution was applied for each sample. The film resiliency was proved using a rapid thermal annealing oven (RTA; PEO 601, ATV Technologie $\mathrm{GmbH}$ ) in $5.0 \mathrm{O}_{2}$ and 5.0 Ar gas flows of ca. $200 \mathrm{I} \mathrm{h}^{-1}$ with a holdtime of 15 minutes in the target temperature. The heating and cooling rates were set to 20 and $25{ }^{\circ} \mathrm{C} \mathrm{min}-1$, respectively. The valence of cobalt and the elemental composition in the film from $\mathrm{Co}(\text { thd })_{2}$-TPA process was investigated with $x$-ray photoelectron spectroscopy (XPS; Kratos Analytical).

\section{Conclusions}

We have here extended the ALD/MLD technology to cover new transition metal components, namely manganese and cobalt, as we successfully developed novel deposition processes for hybrid inorganic-organic $\mathrm{Mn}$-TP and Co-TP thin films. The fact that transition metals in general have many important features in electronics and catalysis due to their partially filled $3 d$ orbitals makes the newly developed hybrid films potential candidates for a variety of future applications.

For the Co-TP films, two precursors were tested; the divalent $\mathrm{Co}(\mathrm{thd})_{2}$ precursor yielded smoother films with a somewhat higher growth-per-cycle rate of $1.5 \AA$ /cycle than the 
trivalent $\mathrm{Co}(\mathrm{acac})_{3}$ precursor. All the three processes, $\mathrm{Mn}$ (thd $)_{3}$-TPA, Co(acac) $)_{3}$ TPA and Co(thd $)_{2}-$ TPA, yielded homogeneous and smooth amorphous films within the deposition temperature range of $200-260{ }^{\circ} \mathrm{C}$. Moreover the films were found to be appreciably stable and proven to endure over moist, oxidizing and reductive conditions. The terephthalate as the organic constituent in the hybrid films is highly interesting due to its high reactivity even with $\beta$ diketonate metal precursors, which previously have been unaccessible for hybrid ALD/MLD depositions, thus considerably expanding the number of possible hybrid precursors. We foresee that other dicarboxylic acids could be interesting candidate precursors as well to be combined with transition metal $\beta$-diketonate (e.g. thd or acac) based precursors for novel ALD/M LD processes to further expand the variety of $A L D / M L D$ chemistries and resultant hybrid film properties.

\section{Acknowledgements}

The present work has received funding from the European Research Council under the European Union's Seventh Framework Programme (FP/2007-2013)/ERC Advanced Grant Agreement (No. 339478). The work also made use of the premises of Aalto University Nanomicroscopy Center (AaltoNMC) and their AFM equipment. Dr. Leena-Sisko Johansson is acknowledged for carrying out the XPS measurements.

\section{Notes and references}

S. M. George, Chem. Rev., 2010, 110, 111-31.

2

V. M iikkulainen, M. Leskelä, M. Ritala and R. L. Puurunen, J. Appl. Phys., 2013, 113, 021301-1-101.

3 M. D. M cDaniel, T. Q. Ngo, S. Hu, A. Posadas, A. A. Demkov and J. G. Ekerdt, Appl. Phys. Rev., 2015, 2, 041301.

4 P. Sundberg and M. Karppinen, Beilstein J. Nanotechnol., 2014, 5, 1104-1136.

5 T. Yoshimura, S. Tatsuura and W. Sotoyama, Appl. Phys. Lett., 1991, 59, 482-484.

6 A. Kubono, N. Yuasa, H.-L. Shao, S. Umemoto and N. Okui, Thin Solid Films, 1996, 289, 107-111.

7 A. A. Dameron, D. Seghete, B. B. Burton, S. D. Davidson, S. Cavanagh, Andrew, J. A. Bertrand and S. M. George, Chem. Mater., 2008, 20, 3315-3326.

8 Q. Peng, B. Gong, R. M. VanGundy and G. N. Parsons, Chem. M ater., 2009, 21, 820-830.

9 A. Sood, P. Sundberg, J. M alm and M. Karppinen, Appl. Surf. Sci., 2011, 257, 6435-6439.

10 O. Nilsen, K. B. Klepper, H. Nielsen and H. Fjellvåg, ECS Trans., 2008, 16, 3-14.

11 J.-P. Niemelä, A. J. Karttunen and M. Karppinen, J. M ater. Chem. C, 2015, 10349-10361.

12 T. Tynell, I. Terasaki, H. Yamauchi and M. Karppinen, J. Mater. Chem. A, 2013, 1, 13619-13624.
T. Tynell, A. Giri, J. Gaskins, P. E. Hopkins, P. M ele, K. M iyazaki and M. Karppinen, J. Mater. Chem. A, 2014, 2, 12150-12152.

E. Ahvenniemi and M. Karppinen, Chem. Commun., 2016, 52, 1139-1142.

Z. Giedraityte, P. Sundberg and M. Karppinen, J. M ater. Chem. C, 2015, 3, 12316-12321.

A. Tanskanen and M. Karppinen, Dalton Trans., 2015, 19194-19199.

M. Nisula and M. Karppinen, ACS Nano Lett., 2016, 16, 1276-1281.

O. Nilsen, H. Fjellvåg and A. Kjekshus, Thin Solid Films, 2003, 444, 44- 51.

K. Klepper, O. Nilsen and H. Fjellvåg, Thin Solid Films, 2007, 515, 7772-7781.

L. B. Backman, A. Rautiainen, M. Lindblad, O. Jylhä and A. O. I. Krause, Appl. Catal. A Gen., 2001, 208, 223-234.

M. Lie, O. Nilsen, H. Fjellvåg and A. Kjekshus, Dalton Trans., 2009, 481-489.

E. Ahvenniemi, M. Matvejeff and M. Karppinen, Dalton Trans., 2015, 44, 8001-8006.

K. B. Klepper, O. Nilsen and H. Fjellvåg, Dalton Trans., 2010, 39, 11628-11635.

L. D. Salmi, M. J. Heikkilä, E. Puukilainen, T. Sajavaara, D. Grosso and M. Ritala, Microporous M esoporous Mater., 2013, 182, 147-154.

L. D. Salmi, M. J. Heikkilä, E. Puukilainen, M. Ritala and T. Sajavaara, J. Vac. Sci. Technol. A, 2015, 33, $01 A 121$.

J. E. Bratvold, G. Carraro, D. Barreca and O. Nilsen, Appl. Surf. Sci., 2015, 347, 861-867.

K. B. Klepper, O. Nilsen, P.-A. Hansen and H. Fjellvåg, Dalton Trans., 2011, 40, 4636-4646.

K. B. Klepper, O. Nilsen, T. Levy and H. Fjellvåg, Eur. J. Inorg. Chem., 2011, 5305-5312.

L. B. Backman, A. Rautiainen, M. Lindblad and A. O. I. Krause, Appl. Catal. A Gen., 2009, 360, 183-191.

M. Diskus, M. Balasundaram, O. Nilsen and H. Fjellvåg, Dalton Trans., 2012, 41, 2439-2444.

M. Yasaka, Rigaku J., 2010, 26, 1-9.

V. Holy, U. Pietsch and T. Baumbach, High Resolution X-ray Scattering from Thin Films and Multilayers, Springer, 1999.

Z.-L. Huang, M. Drillon, N. M asciocchi, A. Sironi, J.-T. Zhao, P. Rabu and P. Panissod, 2000, 2805-2812.

K. B. Klepper, O. Nilsen, S. Francis and H. Fjellvåg, Dalton Trans., 2014, 43, 3492.

M. Ylilammi, Thin Solid Films, 1996, 279, 124-130.

R. L. Puurunen, J. Appl. Phys., 2005, 97, 121301.

M. C. Biesinger, B. P. Payne, A. P. Grosvenor, L. W. M. Lau, A. R. Gerson and R. S. C. Smart, Appl. Surf. Sci., 2011, 257, 2717-2730.

G. S. Hammond, D. C. Nonhebel and C.-H. S. Wu, Inorg. 
Dalton Transactions

Chem., 1963, 2, 73-76. 